\title{
TIRINHAS EM SALA DE AULA: O QUE SABEM OS FUTUROS PROFESSORES DE FÍSICA?
}

\author{
B. V. C. SILVA*, M. C. E. S. ATAIDE e T. K. O. S. VENCESLAU \\ Universidade Federal do Piauí - UFPI \\ boniek@ufpi.edu.br*
}

Artigo submetido em fevereiro/2012 e aceito em junho/2015

DOI: $10.15628 /$ holos.2015.832

\section{RESUMO}

Neste trabalho apresentamos uma pesquisa com 22 alunos da licenciatura em física, na disciplina de Metodologia para o ensino de física, no curso de Física, na Universidade Federal do Piauí. Ela consiste na captação de informação dos futuros professores de física sobre o uso de tirinhas e histórias em quadrinhos com potencialidade de aplicação nas aulas de física. Como um dos principais resultados, notou-se que é de suma importância um momento de reflexão e discussão sobre as potencialidades e dificuldades do uso de tais ferramentas para a efetiva assimilação dos estudantes pesquisados, os quais ou já são ou serão professores de física no ensino médio.

PALAVRAS-CHAVE: Ensino de Ciências, Metodologias do Ensino de Física, Tirinhas.

\section{COMIC STRIPS IN THE CLASSROOM: WHAT THE PHYSICS FUTURE TEACHERS KNOW?}

\begin{abstract}
In this paper we present a research with 22 students in physics degree in the discipline of Teaching Methods of Physics Education, in the Physics Course, at the Piaui Federal University. It consists in obtaining information of future physics teachers on the use of comic strips and comic books with potential application in physics
\end{abstract}

classrooms. As one of the main results, we noted that it is a very important moment of reflection and discussion on the potential and difficulties of using for the effective assimilation of students surveyed who either already are or will be teachers of physical in high school.

KEYWORDS: Science Education, Teaching Methods of Physics, Comic Strips. 


\section{INTRODUÇÃO}

As aulas de ciências vêm sendo alvo de constantes debates em revistas especializadas e em congressos da área. Alguns dos principais resultados relatam desde deficiências nas metodologias de ensino até um possível distanciamento entre os principais resultados das pesquisas em Ensino de Ciências e as salas de aulas (SILVA, 2010).

Dessa forma, as aulas de ciências do ensino básico se apresentam sem significação para os alunos, devido à falta de relação, por exemplo, dos conteúdos científicos estudados e o mundo que os rodeiam (CARVALHO; PEREZ, 2006).

Em outros casos, as aulas estritamente racionais, baseadas na relação teoria-exercícioteoria, em que o aluno é incentivado a memorizar equações e teorias, que fundamentam a resolução de avaliações e exercícios, alguns sem relação com o seu cotidiano, terminam afastandoo do interesse em saber e fazer ciência.

Dessa maneira, em algumas aulas de ciências, são negligenciados fatores inerentes à ciência, a saber: (a) o olhar crítico para o conteúdo estudado, dificultando relações entre o conceito científico trabalhado e o mundo que os rodeia; (b) discussões sobre a natureza do conhecimento científico, reforçando uma ideia de ciência equivocada e (c) utilização de práticas experimentais em sala de aula, impossibilitando ao aluno adquirir um conhecimento empírico ligado à física ou a qualquer outra ciência.

Portanto, mediante as novas necessidades do Ensino de Ciências, devem-se oportunizar ao aluno oportunidades de adquirir um olhar crítico sobre os conteúdos estudados e uma visão mais equilibrada sobre a natureza do conhecimento científico, favorecendo o seu posicionamento de forma satisfatória diante de situações às quais requeiram o uso de conhecimentos sobre a ciência.

Diante disso, novas metodologias devem ser (re) pensadas, visando melhorias no cenário descrito. Uma delas, que apresentamos especificadamente nesse trabalho, poderia ser o uso das tirinhas ou Histórias em Quadrinhos (HQ's) em sala de aula, que discutam ou apresentam situações em que o conhecimento científico se faça necessário para sua compreensão.

Hoje em dia sabemos que as tirinhas ou HQ's, geralmente, fazem parte do cotidiano dos alunos. Devido a sua própria natureza, elas se relacionam com outros saberes de várias áreas do conhecimento, fazendo uma conexão entre os conteúdos conceituais, atitudinais e procedimentais (TESTONI, 2004; CARUSO; CARVALHO, 2005; CARVALHO; MARTINS, 2009; PIZARRO, 2009; CARVALHO; MARTINS, 2013).

As tirinhas e HQ's possuem potencialidades pedagógicas e podem oferecer suporte a novas estratégias didáticas, podendo ser utilizadas tanto nas aulas de ciências como em outras disciplinas. Para Carvalho (2010), já no que diz respeito ao papel dos professores, a utilização de tirinhas e HQ's em sala de aula deve ser um momento de reflexão para os docentes que se propõem em utilizá-las, pois o seu uso não é tarefa trivial.

Atualmente, nas investigações decorrentes das pesquisas em Ensino de Ciências, o uso de tirinhas e HQ's nas aulas de ciências têm tornado a discussão menos incipiente (PIZARRO, 2009). Porém, como relata Carvalho (2010) e Carvalho e Martins (2013), não se percebe a existência de espaços de formação docente, sejam na formação inicial ou continuada, para que os professores 
façam uso dos quadrinhos, mesmo após estes começarem a fazer parte do Programa Nacional Biblioteca na Escola.

Embora como aponte Carvalho (2010), tentativas de discussão sobre o uso dessa ferramenta didática em sala de aula são escassas, nesse trabalho temos como objetivo apresentar o que sabem os licenciandos em física, participantes da disciplina de Metodologia do ensino de física, sobre o uso de tal ferramenta em sala de aula.

Diante disso, surgem duas questões básicas, que enfocaremos nesse trabalho, a saber: como se trabalhar com tirinhas ou HQ's nas aulas de ciências? Qual a contribuição das tirinhas e das HQ's na formação do professor de ciências?

\subsection{As tirinhas e as HQ's no ensino de Ciências e de Física}

Atualmente, as atuais pesquisas sobre o uso das tirinhas e das HQ's nas aulas de ciências, como uma estratégia didática, devido à elevada quantidade de conteúdos científicos que podem ser encontrados nestes materiais.

Hoje tanto as tirinhas como as HQ's são elementos de leitura de crianças, jovens e adultos, sejam no convívio educacional ou social. Entretanto, como é discutido por Higuchi (1997) e Carvalho (2010), a sua implementação nas salas de aula, ainda, são dadas, em alguns casos, como momentos de lazer, entretenimento e descontração.

Nesse trabalho entendemos que as tirinhas e as HQ's não se devem somente se resguardar ao caráter de entretenimento, que também é uma das finalidades delas, mas também observar seus fins educativos, pois elas podem, em muitos casos, mostrar eventos da vivência dos alunos, fazendo relações entre os conceitos físicos e o cotidiano dos discentes. É o que destaca Santos (2013) em seus resultados apresentados na dissertação de mestrado sobre o uso de tirinhas em aulas de física. $\mathrm{O}$ autor relata que as tirinhas e HQ's abordam o cotidiano do aprendiz, em seu enredo, e contribuem para a verbalização dos conceitos cotidianos na sala de aula.

De um lado, sabemos que na maioria das situações do seu dia-a-dia, o conhecimento que prevalece para os alunos é o conhecimento do cotidiano. Esse conhecimento reflete-se de aprendizados adquiridos no convívio familiar, social ou até mesmo escolar. Na física, esses conhecimentos chamam-se de física do cotidiano. Em alguns casos, esses conhecimentos desembocam em erros conceituais ou solidificam-se como concepções alternativas.

Do outro lado, também sabemos que os alunos se utilizam dos conhecimentos científicos, quase que exclusivamente, no contexto escolar, especialmente quando avaliados em provas e exercícios.

Decorrente do exposto acima é necessário um instrumento que sirva de ligação entre esses mundos aparentemente distintos. Acreditamos que as tirinhas e as HQ's possam contribuir nesse sentido. Mas, elas também apresentam outras possibilidades, pois refletem não somente o cotidiano dos alunos, mostrando também ficção científica, sonhos e magia, que permeiam o imaginário dos discentes. Dessa forma, devido ao seu potencial de leitura, elas se tornam um instrumento de aproximação entre os discentes, à aula de física e os docentes.

Já no que diz respeito à Didática das Ciências e especialmente à formação de professores de ciências, as tirinhas e as HQ's oportunizam discussões relevantes para a prática docente, por 
exemplo, o papel do erro, a discussão de analogias na ciência, o trabalho com as concepções alternativas, discussões sobre a História e Filosofia da Ciência, dentre outras.

\section{DESENHO DO ESTUDO: OBJETIVOS, METODOLOGIA E INSTRUMENTOS UTILIZADOS.}

Nesse trabalho apresentamos como objetivo: discutir o que os licenciandos em física sabem sobre a utilização de tirinhas e HQ's em aulas de ciências e, em particular, de física. Esta pesquisa foi desenvolvida com 22 (vinte e dois) alunos da disciplina de Metodologia do Ensino de Física da Universidade Federal do Piauí (UFPI). Essa disciplina tem por objetivo estabelecer uma articulação entre os conhecimentos físicos e da educação, proporcionando uma aproximação entre os conhecimentos físicos e os escolares. No grupo investigado tínhamos já nove alunos que estavam em exercício na rede estadual, já os demais nunca tiveram qualquer experiência em docência.

Dessa forma, a finalidade dessa pesquisa e deste trabalho foi realizar um estudo exploratório sobre o entendimento dos licenciandos em física sobre a utilização de tirinhas e HQ's, bem como possibilitar uma problematização sobre o seu uso em sala de aula, tomando como ponto de partida à experiência e a voz de seus pares.

A investigação se vale de uma abordagem qualitativa, como caracterizada por Marconi (2003) e Moreira (2011) onde existem: (a) preocupação com o processo desenvolvido, e não simplesmente com o produto final; (b) o contato direto do pesquisador com o local que está sendo investigado; (c) a natureza, quase exclusivamente descritiva dos dados e (d) a consideração da variação de pontos de vistas apresentados.

Para acessarmos as concepções dos licenciandos em física sobre a utilização da ferramenta didática discutida nesse trabalho, utilizamos um questionário aberto composto de 4 (quatro) perguntas, que pode ser visto na tabela 1. Escolhemos o questionário aberto, pois ele facilita o acesso às concepções de um grupo no qual o pesquisador não conhece o seu perfil, bem como possibilita uma maior liberdade ao pesquisado ao responder os questionamentos propostos na investigação (RICHARDSON, 1999).

Tabela 1: Objetivos das questões referentes ao instrumento de coleta de dados

\begin{tabular}{l|l}
\hline \multicolumn{1}{c|}{ Questão } & \multicolumn{1}{c}{ Objetivo } \\
\hline $\begin{array}{l}\text { 1. Você já utilizou tirinhas ou Histórias em } \\
\text { Quadrinhos nas suas aulas de Ciências? Se sim, } \\
\text { comente como foi a acolhida por parte dos } \\
\text { alunos. }\end{array}$ & $\begin{array}{l}\text { Investigar se os licenciandos em física já utilizaram } \\
\text { as tirinhas em sala. Observar as dificuldades e as } \\
\text { experiências dos alunos com o uso das tirinhas em } \\
\text { sala de aula. }\end{array}$ \\
\hline $\begin{array}{l}\text { 2. Para você, quais são as principais vantagens e } \\
\text { desvantagens do uso de tirinhas ou Histórias em } \\
\text { Quadrinhos no ensino de Ciências? }\end{array}$ & $\begin{array}{l}\text { Observar o entendimento dos licenciandos em } \\
\text { física sobre as principais dificuldades e vantagens } \\
\text { da utilização das tirinhas em sala de aula. }\end{array}$ \\
\hline $\begin{array}{l}\text { 3. Para você que instrumentos as Histórias em } \\
\text { Quadrinhos ou as tirinhas devem possuir para } \\
\text { facilitar a aprendizagem de conteúdos } \\
\text { relacionados à ciência, em geral, e, a física, em } \\
\text { particular. }\end{array}$ & $\begin{array}{l}\text { Observar os elementos constituintes das tirinhas e } \\
\text { das histórias em quadrinhos que viabilizam suas } \\
\text { utilizações em sala de aula. }\end{array}$ \\
\hline $\begin{array}{l}\text { 4. Para você, as Histórias em Quadrinhos e as } \\
\text { tirinhas podem servir como um elo entre a física e } \\
\text { outras formas de cultura, por exemplo, a } \\
\text { literatura? Explique. }\end{array}$ & $\begin{array}{l}\text { Investigar se os licenciandos em física percebem a } \\
\text { natureza interdisciplinar das tirinhas e das HQ's. }\end{array}$ \\
\hline
\end{tabular}




\section{UMA PESQUISA SOBRE AS TIRINHAS: ANALISANDO OS RESULTADOS}

Embora a nossa investigação tenha uma natureza qualitativa, trazemos também dados quantitativos, que segundo Gibbs (2009), estes dados têm significados e necessitam também de interpretação para auxiliar na elucidação do problema de pesquisa. Dessa forma, aqui, eles receberão atenção especial, pois serviram como norte para a investigação.

A primeira questão do instrumento avaliativo pretendia investigar se os futuros professores de física já tinham utilizado tirinhas em suas aulas de física, além de observar as dificuldades e as experiências dos alunos com o uso das mesmas.

Como resultado temos que poucos alunos da pesquisa possuíam experiência em sala de aula, contabilizando 4 (quatro) alunos ou $16 \%$ e, destes, somente 1(um) aluno já tinha utilizado tirinhas, esta usada como questão em suas avaliações bimestrais.

Observem o depoimento deste aluno: "Se tratava de um conteúdo conhecido como dilatação linear. A tirinha era uma ficção meio exagerada, mas serviu para os alunos entenderem melhor o conteúdo; boa parte dos alunos (75\%) pediram novas tirinhas para verem".

Já, os demais alunos, não conheciam ou nunca discutiram sobre a possibilidade do uso de tirinhas ou HQ's em aulas de física.

A segunda questão pretendia investigar o entendimento dos alunos sobre as principais vantagens e desvantagens do uso de tirinhas em sala de aula. Na tabela 2, apresentamos os principais resultados encontrados.

Tabela 2: Vantagens e Desvantagens do uso de tirinhas em sala de aula. Observem que a soma das frequências soma mais que a quantidade de alunos (22alunos). Isso ocorreu devido alguns alunos apontarem várias vantagens e desvantagens para o uso das tirinhas ou HQ's

\begin{tabular}{c|c|c|c}
\hline Vantagens & Frequência & Desvantagens & Frequência \\
\hline $\begin{array}{c}\text { Facilita a compreensão } \\
\text { dos assuntos estudados }\end{array}$ & 12 & $\begin{array}{c}\text { Dificuldade de } \\
\text { elaboração de questões } \\
\text { sobre as tirinhas }\end{array}$ & 14 \\
\hline $\begin{array}{c}\text { Possibilita relacionar o } \\
\text { conteúdo com o dia-a- } \\
\text { dia do aluno }\end{array}$ & 10 & $\begin{array}{c}\text { Dificulta apresentações } \\
\text { de forma quantitativa } \\
\text { (uso de equações) }\end{array}$ & 4 \\
\hline $\begin{array}{c}\text { Introduz conteúdos de } \\
\text { forma lúdica }\end{array}$ & 8 & $\begin{array}{c}\text { Pode possibilitar uma } \\
\text { interpretação } \\
\text { equivocada do assunto } \\
\text { estudado. }\end{array}$ & 4 \\
\hline $\begin{array}{c}\text { Torna a aula mais } \\
\text { descontraída e } \\
\text { divertida }\end{array}$ & 10 & $\begin{array}{c}\text { Dificuldade de } \\
\text { interpretações das } \\
\text { tirinhas. }\end{array}$ & 3 \\
\hline $\begin{array}{c}\text { Serve para mapear as } \\
\text { concepções } \\
\text { alternativas dos alunos }\end{array}$ & 6 & $\begin{array}{c}\text { Dificulta relacionar o } \\
\text { conteúdo físico com o } \\
\text { conteúdo da tirinha. }\end{array}$ & 5 \\
\hline $\begin{array}{c}\text { Prende a atenção dos } \\
\text { alunos na sala de aula }\end{array}$ & 14 & \multicolumn{1}{|}{}
\end{tabular}

A terceira questão do instrumento tinha o objetivo de verificar as características que as tirinhas e as HQ's devem possuir para que possam ser utilizadas em sala de aula. Observem os principais resultados na tabela 3. 
Tabela 3: Elementos constituintes das tirinhas. Observem que o somatório das frequências é maior que o número de participantes $(n=22)$, pois alguns deles apontaram mais de um elemento

\begin{tabular}{c|c}
\hline Características das tirinhas e HQ's & Frequências \\
\hline Devem ser engraçadas & 15 \\
\hline Precisa envolver as concepções alternativas & 10 \\
\hline Deve apresentar os conceitos físicos de forma clara & 12 \\
\hline
\end{tabular}

Podemos observar, nas tabelas 2 e 3, a referência direta ao entendimento dos licenciandos em física sobre o uso das tirinhas. Para uma boa parte dos pesquisados, as tirinhas e as HQ's deveriam ser introduzidas ao início das aulas, principalmente como um elemento motivador ou de descontração, tornando as aulas mais dinâmicas.

Outro motivo para a sua introdução no início das aulas - $65 \%$ dos pesquisados - seria a possibilidade de captação das concepções alternativas. Para o grupo investigado, as aulas se tornariam mais interessantes se eles - os professores - inicialmente soubessem o que os alunos pensam sobre o conteúdo físico que será trabalho. Dessa forma, ainda para os pesquisados, as tirinhas e as HQ's serviriam como ponto de partida de estratégias didáticas que viabilizariam o processo de construção de conteúdos físicos.

Já para o segundo bloco - 35\% dos pesquisados -, que argumentaram para a utilização das tirinhas e HQ's no final das aulas, elas serviriam como questões avaliativas, potencializando a aproximação da física com o cotidiano dos alunos, ou como momentos de revisão, servindo para verificar tanto o nível de aprendizagem dos alunos como a viabilidade das suas metodologias e estratégias didáticas usadas em sala de aula.

Também foi possível observar a divisão de dois blocos no que diz respeito ao conteúdo físico, descrito nas tirinhas e HQ's. Para um bloco de pesquisados - $60 \%$ dos participantes -, elas devem apresentar conceitos físicos corretos e precisos, pois a imprecisão conceitual poderá facilitar a incompreensão do conteúdo que será estudo. Para os demais - $40 \%$ dos participantes -, é viável que as tirinhas apresentem algum grau de imprecisão conceitual, pois possibilita momentos de discussão sobre o erro contido nelas, bem como possibilita a captação de concepções alternativas.

Por fim, apresentamos a análise da última questão (Para você, as histórias em quadrinhos e as tirinhas podem servir como um elo entre a física e outras formas de cultura, por exemplo, a literatura? Explique.) que objetivou analisar se o grupo investigado observa a natureza interdisciplinar das HQ's e das tirinhas. Abaixo, apresentamos algumas das respostas.

Aluno A: Eu acredito que as tirinhas, que usamos em sala de aula, podem reviver o prazer de ler em sala de aula. Eu acho que pode melhorar as aulas de português e de física.

Aluno C: Eu acho que sim, porque podemos mostrar que física é cultura de um povo e é usada todo dia e lida todo dia nos jornais.

Aluno L: Eu acho que com as tirinhas podemos ministrar uma aula só de várias disciplinas como física, química, biologia e português. 
Aluno $\mathrm{H}$ : Eu acho que elas podem unir as ciências da natureza com as outras áreas, pois é normal você dividi as aulas de história, de física e de português. Acho que assim juntamos tudo.

Um fato interessante é que todos os participantes da pesquisa observam a natureza interdisciplinar das HQ's e das tirinhas, apontando o potencial dessa ferramenta didática no que diz respeito a sua utilização em sala de aula.

No tópico abaixo faremos as nossas considerações finais.

\section{CONSIDERAÇÕES FINAIS}

Entendemos que mudanças didáticas não fáceis ou triviais. Mas, compreendemos que professores devem ser constantemente instigados a procurar novas metodologias de ensino que fundamentem estratégias inovadoras mais motivantes e participativas para os alunos.

Outro ponto relevante que defendemos aqui é que os cursos de licenciatura em ciências (física, química, biologia e ciências da natureza) ofereçam subsídios para a formação de um professor-pesquisador, que seja capaz de pesquisar, avaliar e modificar a sua prática docente.

Dessa forma, devem-se oferecer momentos de reflexão para que os futuros professores de ciências conheçam as metodologias de ensino inovadoras, dentre elas, as tirinhas e HQ's. Para tanto, é preciso inseri-los no campo das pesquisas em Ensino de Ciências, facilitando a compreensão e o entendimento das novas pesquisas e, principalmente, discutindo a sua possibilidade de inserção em sala de aula.

Portanto, esperamos assim aperfeiçoar a relação entre a pesquisa em Ensino de Ciências e a sala de aula, melhorando tanto a prática efetiva dos docentes em sala como criando ambientes de pesquisa sobre a sua prática docente.

Por fim, no que diz respeito ao uso das tirinhas e das HQ's em sala de aula, entendemos que ela não pode ser encarada como a redentora da educação, mas sim como mais uma possibilidade, dentre várias, de se trabalhar os conceitos científicos em sala de aula.

\section{REFERÊNCIAS BIBLIOGRÁFICAS}

1. CARVALHO, A. M. P; GIL-PÉREZ, D. Formação de professores de Ciências. Tradução de Sandra Valenzuela. São Paulo: Cortez, 1993.

2. CARVALHO, L. S; MARTINS, A. F. P. Os quadrinhos nas aulas de Ciências Naturais: uma história que não está no gibi. Revista Educação em Questão, v. 35, n. 21, p. 120-145. maio/ago. Natal: EDUFRN, 2009.

3. CARVALHO, L. S.; MARTINS, A. F. P. . Formação continuada com quadrinhos nas aulas de ciências: algum problema?. Linhas Críticas (UnB), v. 19, p. 331-353, 2013.

4. CARUSO, F.; CARVALHO, M.; SILVEIRA, M. C. Ensino não-formal no campo das ciências através dos quadrinhos. Ciência e Cultura, Campinas, v. 57, n. 4, p. 33-35, 2005.

5. GIBBS, G. Análise de dados qualitativos. Porto Alegre: Artmed Editora, 2009.

6. MARCONI, M. A. Fundamentos de metodologia científica. São Paulo: Atlas, 2003. 
7. MOREIRA, M. A. Metodologias de Pesquisa em Ensino. São Paulo: Editora Livraria da Física, 2011.

8. PIZARRO, M. V. Histórias em quadrinhos e o ensino de Ciências nas séries iniciais: estabelecendo relações para o ensino de conteúdos curriculares procedimentais, 2009. 188f. Dissertação (Mestre em Educação para a Ciência) - UNESP, Faculdade de Ciências, Bauru, 2009.

9. RICHARDSON, R. Questionário. In: Pesquisa social. São Paulo: Atlas, 1999.

10. SANTOS, D. R. Limites e potencialidades do uso de tirinhas na significação de conceitos de física no Ensino Médio, 2013, 82 fls. Dissertação (Mestrado em Educação nas Ciências). Universidade Regional do Noroeste do Estado do Rio Grande do Sul. Rio Grande do Sul, 2013.

11. SILVA, B. V. C. A natureza da ciência pelos alunos do ensino médio: um estudo exploratório. Latin American Journal of Physics Education, v.4, n.3, p. 670-677, 2010.

12. TESTONI, L. A. Um corpo que cai: As Histórias em Quadrinhos no Ensino de Física, 2004, 158 fls. Dissertação (Mestrado em Educação). Faculdade de Educação da Universidade de São Paulo, São Paulo, 2004.

\section{ANEXO}

\section{QUESTIONÁRIO SOBRE O USO DAS TIRINHAS EM SALA DE AULA}

1. Você já utilizou tirinhas ou Histórias em Quadrinhos nas suas aulas de Ciências? Se sim, comente como foi a acolhida por parte dos alunos.

2. Para você, quais são as principais vantagens e desvantagens do uso de tirinhas ou Histórias em Quadrinhos no ensino de Ciências?

3. Para você que instrumentos as Histórias em Quadrinhos ou as tirinhas devem possuir para facilitar a aprendizagem de conteúdos relacionados à ciência, em geral, e, a física, em particular.

4. Para você, as Histórias em Quadrinhos e as tirinhas podem servir como um elo entre a física e outras formas de cultura, como por exemplo, a literatura? Explique. 